\title{
REVISIONISMO HISTÓRICO EN ARQUITECTURA EN EL INTERSTICIO DE LOS SIGLOS XX Y XXI: REIVINDICAR, RESCATAR O NEGAR UNA MEMORIA
}

Revisionismo histórico na arquitetura no interstício dos séculos XX e XXI: reivindicar, resgatar ou negar uma memória

Historical revisionism on architecture, at the interstice of the 20th and 21st centuries: vindication, rescue or denial of memory

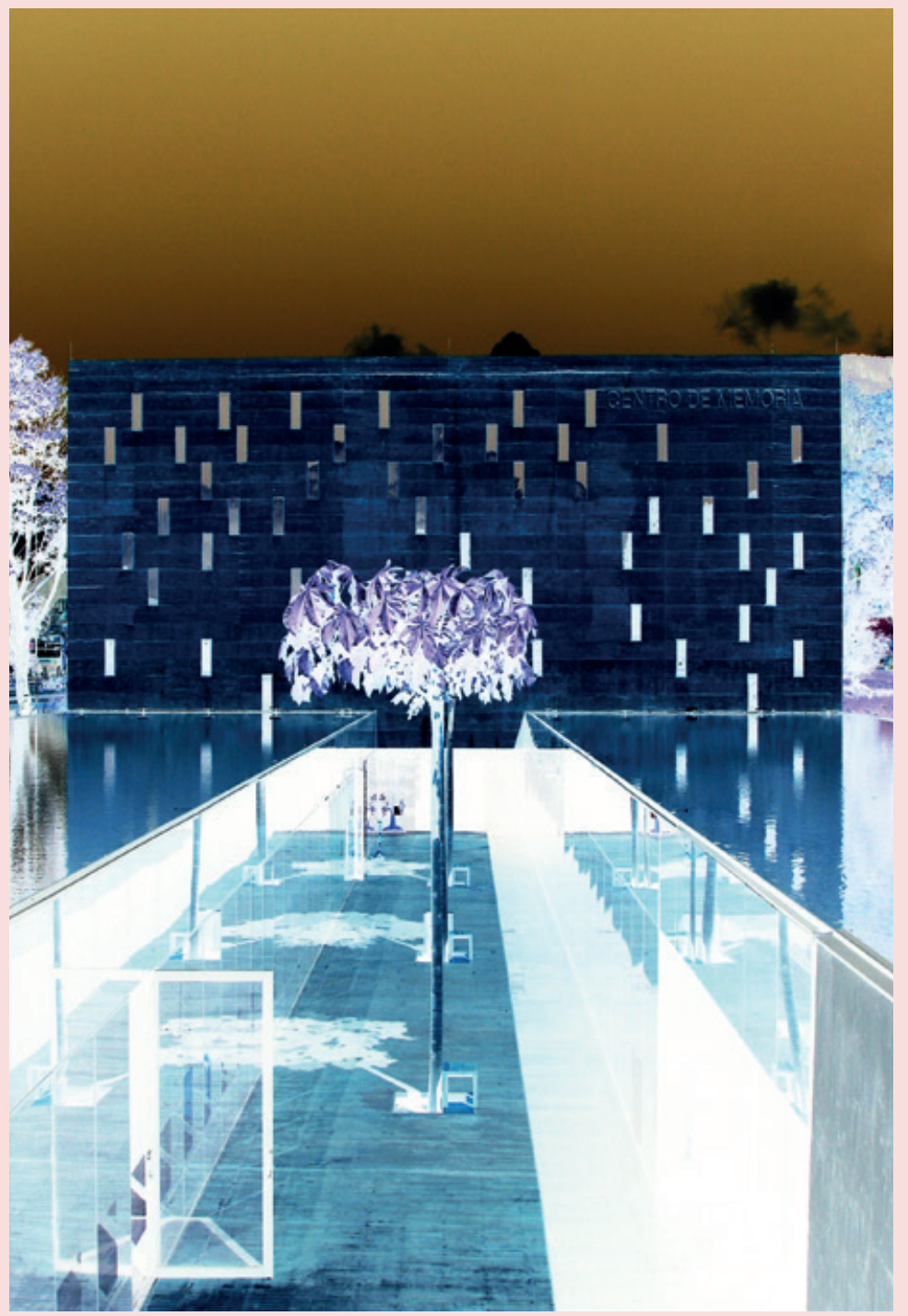

William García Ramirez

Profesor, Investigador Facultad de Arquitectura y Diseño. Pontificia Universidad Javeriana. Bogotá, Colombia. william.garcia@javeriana.edu.co

https://orcid. org/0000-0002-0434-0358

Artículo resultado de la investigación titulada: Análisis de las memorias descriptivas, políticas de museos y Planimetrías en las Bienales Colombianas de Arquitectura: Arquitectura de los Museos (1970-2018) ID PRY 9700.

Entidad financiadora: Pontificia Universidad Javeriana.

Imagen negativo Centro Memoria, Paz y Reconciliación Bogotá. Arg. Juan

Pablo Ortiz.

Fuente: Arg.

William Garcí

Ramírez. 


\title{
RESUMEN
}

El revisionismo histórico, fenómeno propio de las ciencias sociales y políticas, se ha venido consolidando a comienzos del siglo XXI como una de las estrategias paradigmáticas en arquitectura, con el propósito de rescribir (o borrar) memorias históricas de la ciudad. En ese contexto, el objetivo de la investigación aquí expuesta fue indagar sobre la relación entre distintas coyunturas sociales y políticas convergentes en el tema de la memoria y la demolición / construcción de arquitecturas, como estrategia para interrogar hechos del pasado y cuestionar las narrativas oficiales. Tratándose de una investigación historiográfica, la metodología se sustentó en un análisis cruzado entre los discursos con los que se han argumentado distintas problemáticas sociopolíticas en torno a la memoria, acontecidas en diferentes países, y los proyectos arquitectónicos construidos o demolidos a propósito de tales problemáticas. Las conclusiones, en tanto aporte de la investigación, permitieron detectar tres vertientes del revisionismo histórico en arquitectura, a partir de su uso (y abuso) en relación con la historiografía de los hechos: reivindicación, rescate y negación de la memoria.

Palabras Clave: Revisionismo histórico, crítica de la arquitectura, demolición, historia de la arquitectura, memoria

\section{RESUMO}

O revisionismo histórico, fenômeno típico das ciências sociais e políticas, vem se consolidando no início do século XXI como uma das estratégias paradigmáticas da arquitetura, com o propósito de reescrever (ou apagar) memórias históricas da cidade. Nesse contexto, o objetivo da pesquisa aqui apresentada foi investigar a relação entre diferentes conjunturas sociais e políticas convergentes sobre o tema da memória e a demolição / construção de arquiteturas como estratégia para interrogar acontecimentos do passado e questionar narrativas oficiais. Por se tratar de uma pesquisa historiográfica, a metodologia baseou-se no cruzamento dos discursos com os quais têm sido discutidos diversos problemas sociopolíticos em torno da memória, ocorridos em vários países, com os projetos arquitetônicos construídos ou demolidos como consequência desses debates. As conclusões, como contribuição da pesquisa, permitiram detectar três tendências do revisionismo histórico na arquitetura, a partir de seu uso (e abuso) no que tange à historiografia dos fatos: reivindicação, resgate e negação da memória.

Palavras-Chave: Revisionismo histórico, crítica da arquitetura, demolição, história da arquitetura, memória

\begin{abstract}
Historical revisionism, a phenomenon typical of social and political sciences, has been consolidated at the start of the $21^{\text {st }}$ century as one of the paradigmatic strategies in architecture, with the purpose of rewriting -or erasing- historical memories of the city. In this context, the objective of the research presented here was to investigate the relationship between different convergent social and political situations on the issue of memory and the demolition/construction of architectures, as a strategy to question events from the past and the official narratives. As this is a historiographic research, the methodology used a cross analysis between the discourses on which several socio-political issues around memory, that occurred in different countries, have been based, and the architectural projects built or demolished because of these issues. The conclusions, insofar as a research contribution, allowed detecting three lines of historical revisionism in architecture, starting from its use -and abuse- regarding the historiography of the facts: vindication, rescue, and denial of memory.
\end{abstract}

Keywords: Historical revisionism, architecture critique, demolition, history of architecture, memory 


\section{INTRODUCCIÓN}

En abierto desafío al paradigma del confinamiento, al que la sociedad mundial se vio de repente sometida en 2020, gran parte de esta sociedad decidió arriesgar su propia salud, para salir a las calles a protestar por hechos en los que se han revelado injusticias. Desde las protestas en contra del racismo a cargo del movimiento Black Lives Matter en Estados Unidos, hasta el repudio por el esclavismo en Europa, una de las estrategias que más se ha visibilizado tiene que ver con acciones revisionistas, en las que estatuas y monumentos instalados en espacios públicos, han sido derribadas como fórmula de juicio social y político a figuras del pasado. Pareciera que el confinamiento, el encierro, la imposibilidad de mirar hacia afuera, nos ha llevado a mirarnos hacia adentro, a cuestionarnos, a revisarnos, a ver en los espacios de las ciudades, lo que siempre ha estado allí, para examinarlo detenidamente. La ciudad se ha convertido no solo en territorio de las discusiones y protestas, sino en campo de disputa de las narrativas existentes que, a través del arte y la arquitectura, cuentan una historia, una verdad; parques y edificios, que, como páginas de un libro, se han empezado a releer y a cuestionar.

Latinoamérica no ha sido ajena a estas acciones. El pasado 16 de septiembre de 2020, después de un juicio sumario, un grupo de indígenas Misak decidió derribar en la ciudad de Popayán (Colombia) la estatua del "conquistador" español Sebastián de Belalcázar. Esta acción dividió las opiniones a favor y en contra, pues mientras unos reconocían en este derribo un acto de justicia, otros lamentaban el daño de una pieza de arte que por décadas hacía parte del espacio público de esta ciudad; lo que abre la pregunta sobre cómo valorar estas obras. Al respecto, vale la pena considerar el caso del Valle de los Caídos, obra impulsada por y durante la dictadura de Francisco Franco. Allí la ley determinó "... la retirada de escudos, insignias, placas y otros objetos o menciones conmemorativas de exaltación, personal o colectiva, de la sublevación militar, de la Guerra Civil y de la represión de la Dictadura...", exceptuando el retiro y ocultamiento de estas obras, en dos casos específicos: "cuando las menciones sean de estricto recuerdo privado, sin exaltación de los enfrentados, o cuando concurran razones artísticas, arquitectónicas o artístico-religiosas protegidas por la ley" (Gobierno de España, 2017, Art. 15).

Así, el revisionismo histórico contemplado en esta ley pone en la balanza cuestiones ideológicas frente a aspectos artísticos y arquitectónicos, y, salomónicamente, resuelve valorar los objetos y edificios a partir de sus cualidades físicas, no solo por su significación o connotación ideológica. En principio, puede afirmarse que todo ejercicio historiográfico implica un acto de revisionismo, pues cada tema histórico es susceptible de ser re-considerado a la luz de los intereses de cada historiador para construir una narrativa en particular. Empero, John Morrill contextualiza de manera más precisa este fenómeno en el campo de la historia: 


\begin{abstract}
El revisionismo fue una revuelta contra las historias e historiografías materialistas o deterministas, la mayoría de los períodos y escuelas de historia han tenido su momento revisionista. En muchos casos, fue directamente una revuelta contra las historiografías marxistas (como en el caso de Francia); o contra las historiografías nacionalistas (como en Irlanda); o contra las historias partidistas, con sus fuertes teleologías y grandes narrativas de progreso... (Morrill, 2015, p.577) ${ }^{1}$
\end{abstract}

De este modo, el revisionismo surge como sana desconfianza ante la posibilidad de una historiografía totalizante que, en su afán absolutista, pudiera omitir hechos disonantes en contra de la uniformidad que supone una historiografía determinista. En estos términos, la lógica esencial que mueve al revisionismo radica en un permanente estado de sospecha y no necesariamente como crítica a una visión específica de la historia.

En arquitectura, la actitud revisionista acontece indistintamente si se trata de un discurso hegemónico o no, pues su actitud no es tanto crítica como comprehensiva de los valores que en un presente hacen consenso en una sociedad; valores con los que se promueve, a través de la arquitectura, la reivindicación y el rescate de una memoria, aunque también en algunos casos el afán por negar dicha memoria.

El campo de acción del Revisionismo se sitúa, por tanto, en el ámbito de la memoria, pues es en los acontecimientos pasados donde es posible recuperar y validar una serie de narrativas historiográficas como manifestación de posturas sociales, culturales y políticas invisibilizadas, quizá olvidadas y, por ello, ignoradas. No obstante, la memoria también es un mecanismo flexible que permite una permanente consulta y cuestionamiento: "La memoria en cuanto Ars (arte) es vista como un depósito de saber en el que se puede almacenar información y así mismo como una capacidad de evocarla de nuevo" Erll (20I2, p. 4I). Así, la memoria histórica es tanto fuente de respuestas, como motivo de preguntas que cuestionan tales respuestas, de allí que "El camino a la memoria es resbaladizo, particularmente en países donde las historias sobre el pasado han sido reprimidas o sumergidas durante más de una generación" Von Henneberg (2004, p. 4I)². Pero la memoria no solo reposa en archivos y bibliotecas sino en las personas, es por ello que la memoria en cuanto Agere (hacer), deriva en el acto de agenciar, de "agenciamiento", en la "capacidad del sujeto para generar espacios críticos no hegemónicos de enunciación del yo, en y desde lo colectivo, que retan visiones normativas y/o hegemónicas de la historia" (Museo Reina Sofía - Subtramas).

De esta manera, el ámbito de la memoria constituye un campo cíclico, una suerte de uróboro en el que recuerdo y olvido se trenzan 
en constante disputa, en la que en ocasiones vence el recuerdo y en otras el olvido. En arquitectura, este uróboro se sitúa en la sucesiva construcción y demolición de edificios como condición natural del crecimiento de las ciudades, sin considerar que con ello la arquitectura también contribuye a escribir, pero también a borrar la memoria de las ciudades. Al respecto, Montaner y Muxi señalan:

... a partir de la década de 1990 este concepto (de memoria)
se ha ido deconstruyendo en dos direcciones opuestas; por
un lado, por parte del sistema productivo, se han reforzado
los mecanismos de borrado y sustitución de la memoria y, por
otro, por parte de los movimientos sociales, se ha reivindicado
la diversidad de memorias existentes en cada ciudad, defen-
diendo su visibilización y desvelando cómo conviven o cómo
unas se imponen sobre las otras (Montaner Muxi, 20 I l, p. 70).

Es precisamente este último aspecto, cómo unas memorias se imponen a otras en arquitectura, el que constituye una de las preguntas que orienta esta investigación, pues de manera casi unánime, hemos aceptado el precepto según el cual las ciudades y la arquitectura de la ciudad son un palimpsesto, una superposición de hechos construidos que sucesivamente que se mezclan y se confunden unos con otros, sin preguntarnos por las implicaciones que para la historia y, por ende, para el futuro de una ciudad, entraña el que unas memorias se apaguen para encender otras nuevas.

Por ello, las ciudades entendidas como palimpsestos ofrecen un campo inusitado para la intervención arquitectónica desde sus pentimentos, es decir, desde acontecimientos - generalmente lamentables- de orden social, político o cultural que han quedado ocultos. El revisionismo histórico de estos pentimentos, de estos errores ocultos, ha llevado en ocasiones a juzgarlos como actos fallidos, por lo que es en esos fallos donde surge una oportunidad de intervención que subsane y les repare por medio de una intervención arquitectónica. Dichos fallos no aluden solamente a equivocaciones de tipo material (destrucción de un patrimonio urbano o arquitectónico) a su acepción en tanto dictámenes (sentencias y juicios donde se detectan violencias, injusticias o silenciamientos), por lo que es a partir de estas equivocaciones de orden material y social, desde donde se detonan acciones de arquitectura tendientes a reivindicar $y / o$ a rescatar estas pérdidas.

El caso del levantamiento (y caída) del muro de Berlín es apenas uno de los ejemplos en los que se evidencia esta condición de activar y desactivar una memoria: un ejercicio de poder que implicó levantar un muro que dividió a toda una ciudad, creando una frontera artificial, para posteriormente, ser derribado, en un contra-ejercicio de poder, como resignificación de un hecho físico que connotaba una serie de valores abiertamente antidemocráticos. Empero, llama signi- 


\section{METODOLOGÍA}

AS / Vol. 39. No59 / ENERO 2021 // ISSN impresa 0716-2677 / ISSN digital 0719-6466 


\section{RESULTADOS}

REVISIONISMO HISTÓRICO COMO REIVINDICACIÓN DE UNA MEMORIA A TRAVÉS DE LA ARQUITECTURA
- FASE 2: Recolección y sistematización de la información referida a coyunturas históricas de alto impacto en la sociedad, en el contexto de los criterios establecidos por Aguilar-Forero (20|8), acontecidas durante el siglo XX y hasta la actualidad.

- FASE 3: Recolección y sistematización de la información referida a proyectos arquitectónicos y urbanos en los que se evidencia una relectura de hechos históricos y de memoria en las ciudades.

- FASE 4: Análisis de los proyectos (recolectados en la fase 3) en el contexto histórico en medio del cual surgen los encargos arquitectónicos.

- FASE 5: Elaboración de conclusiones a partir de las vertientes detectadas del revisionismo histórico en arquitectura, en relación con las coyunturas históricas en las que se han contextualizado, teniendo en cuenta la hipótesis planteada en la investigación.

Esta vertiente se inscribe en lo que se ha denominado como el "boom de la memoria", una propensión hacia el pasado [Figura I].

\footnotetext{
... que estalla por todas partes en la forma del auge de la novela histórica y los relatos biográficos, la moda retro en arquitectura y vestidos, el entusiasmo por las conmemoraciones, el auge de los anticuarios, el crecimiento y expansión de los museos en las tres últimas décadas, la restauración esteticista de los viejos centros urbanos, hasta el video como dispositivo de memorialización e, incluso, la conversión del pasado del mundo en banco de datos. (Martín Barbero, 2010, p. 17)
}

En un contexto más acotado, se trata de un revisionismo histórico que apunta a la reivindicación de derechos sociales, políticos y/o culturales que han sido vulnerados a los ciudadanos, por parte de organismos estatales y/o de organizaciones al margen de la ley, de acuerdo con lo postulado por Aguilar-Forero (20|8).

Dado que "el olvido tiene lugar -o tiene "un" lugar, pero precisamente dónde nadie parece estar seguro, excepto por la estela vacía que éste deja" (Klein, 20 I0, p. 209), es preciso para esta reivindicación de derechos, proveer de un lugar físico donde albergar el olvido: El museo de memoria. Lugar donde la sociedad va a recordar, a mirarse a sí misma en el espejo de su pasado.

La conmemoración de estos puncta dolentia en distintas partes del mundo ha contribuido a consolidar una de las tipologías que más caracteriza al panorama de la arquitectura contemporánea: los Museos de la memoria. Se trata de una arquitectura respaldada generalmente desde el Estado, derivada de hechos de guerra, conflictos u holocaustos. En países como Colombia, este respaldo ha sido producto de dos hechos fun- 
damentales en su historia reciente: La celebración del Bicentenario de Independencia (2019) y la firma de los Acuerdos de la Habana (20 I6). En uno y otro evento se convoca de manera oficial a la arquitectura, como estrategia de reparación y conmemoración en el reconocimiento de un pasado, pues a través de la arquitectura del museo, se busca "musealizar" la memoria, es decir, "una forma particular de construcción y legitimación de la memoria colectiva" (Jaramillo y Del Cairo, 2013, p. 76).

De esta manera, la arquitectura del museo se ve reconfigurada más allá de su vocación tradicional como templo de las artes para asumir el reto de constituirse en "escenario formal de los nuevos relatos colectivos" (Fernández-Galiano, 2009, p. 3). Una arquitectura que tiene el reto, no solo de exponer hechos, sino de recrear la experiencia

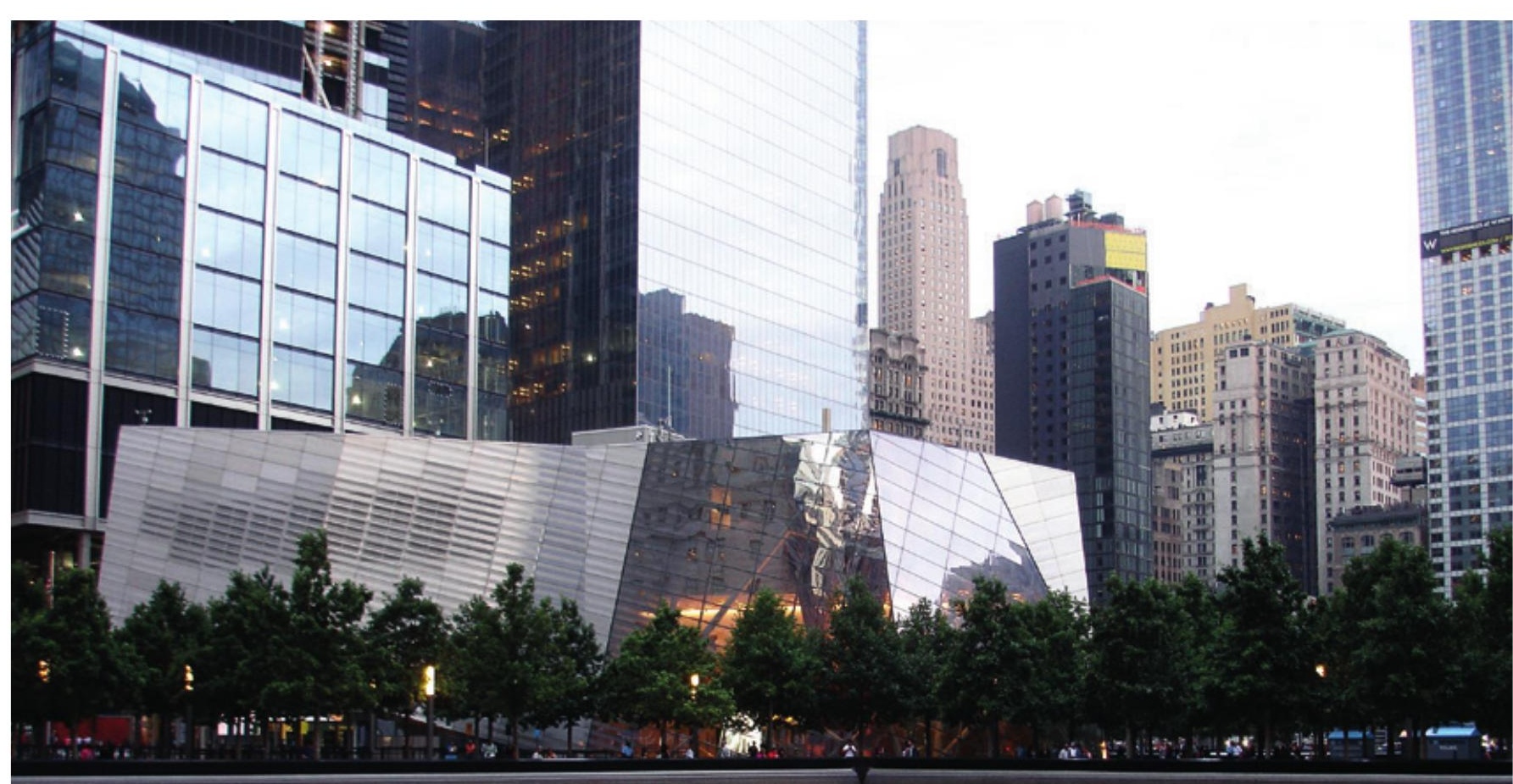

AS / Vol. 39. No59 / ENERO 2021 // ISSN impresa 07 I 6-2677 / ISSN digital 07 I9-6466 


\section{REVISIONISMO HISTÓRICO COMO RESCATE DE UNA MEMORIA A TRAVÉS DE LA ARQUITECTURA}

de estos hechos con el fin de producir un efecto de recuerdo y reconocimiento y -a largo plazo- un efecto de perdón y sanación. En este sentido, se trata de arquitecturas cuyas estrategias proyectuales apuntan a materializar el recuerdo, a través del diseño experiencial de los recorridos y de los espacios de reflexión, con el fin de contar y enseñar a sus visitantes una historia otra. De allí que el sentido de los museos de la memoria sea de orden pedagógico y, aunque todo proceso de aprendizaje implica un principio de imitación de lo aprendido, en este tipo de museos sucede lo contrario: se trata de museos que enseñan lo que no se debe repetir jamás.

El equilibrio entre simbolismo y monumentalidad otorga a los museos de la memoria ese necesario balance entre intimidad y evocación para la reflexión sobre hechos dolorosos; espacios de acceso público cuya atmósfera invita a la conmemoración de las víctimas y, en particular, a la reivindicación de una serie de hechos en los que se evidencian facetas no reveladas - o reveladas parcialmente-. Por ello, un museo de la memoria se puede definir como un espacio donde se reivindica un tiempo.

A continuación, en la Tablal se presenta una relación de los principales lugares reivindicativos de una memoria, construidos en el mundo desde los años 50 del siglo XX hasta la actualidad. Una lectura de los discursos argumentativos de estos proyectos revela cómo el diseño arquitectónico guarda relación con la narrativa con la que se busca reivindicar una memoria. Así, los proyectos de carácter más abierto y público, como el Monumento del Holocausto (Peter Eisenman - Berlín), reivindican la memoria de las víctimas mediante una narrativa unívoca sustentada en la idea de monumento. Por el contrario, los proyectos construidos en edificios, y con acceso limitado al público, presentan una narrativa plural y, en general, abierta a una permanente revisión, pese a que cuentan con un guion museográfico preestablecido.

A través de la historia algunos arquitectos, tal vez sin proponérselo, han atentado contra la ciudad a través de intervenciones arquitectónicas, cuyas consecuencias en términos de memoria histórica hoy se lamentan, por lo que el revisionismo como rescate de la memoria, implica el acto de recobrar memorias perdidas e invisibilizadas de la ciudad, mediante intervenciones en el espacio. Se trata de proyectos con los que se busca recuperar una memoria de la ciudad, por causa de una obra realizada en el pasado, y que en la actualidad se juzga a todas luces inconveniente, aunque en su momento se considerara una intervención acertada. Un ejemplo de esta vertiente revisionista se encuentra en los cientos de kilómetros de viaductos y autopistas elevadas que han sido demolidas en distintas ciudades del mundo para dar lugar -ya no al automóvil, la condición de lo privado- sino al peatón, la condición de lo público. Multimillonarias inversiones que en su época se consideraron como un gran acierto y un magnífico avance, hoy son vistas como agresivas intervenciones que alteran el paisaje y la calidad de vida. No 
Tabla 1

Revisionismo histórico como negación de una memoria a través de la arquitectura.

Fuente: Elaboración del autor.

\begin{tabular}{|c|c|c|c|c|}
\hline Año & Proyecto & $\begin{array}{c}\text { Relacion Arquitectura } \\
\text { Narrativa }\end{array}$ & Arquitecto & Ciudad - País \\
\hline 2017 & $\begin{array}{l}\text { Monumento Nacional Canadiense al } \\
\text { Holocausto }\end{array}$ & $\begin{array}{l}\text { Espacio Público - Narrativa } \\
\text { Unívoca }\end{array}$ & Daniel Libeskind & Ottawa - Canadá \\
\hline 2016 & Casa de la Memoria Remanso de Paz & $\begin{array}{l}\text { Espacio Museo - Narrativa } \\
\text { Plural }\end{array}$ & Taller Síntesis & Turbo - Colombia \\
\hline 2014 & $\begin{array}{l}\text { Museo Canadiense de los Derechos } \\
\text { Humanos }\end{array}$ & $\begin{array}{l}\text { Espacio Museo - Narrativa } \\
\text { Plural }\end{array}$ & Antoine Predock & Winnipeg - Canada \\
\hline 2014 & $\begin{array}{l}\text { Memorial Nacional del } 11 \text { de } \\
\text { Septiembre - Memorial Plaza }\end{array}$ & $\begin{array}{l}\text { Espacio Público - Narrativa } \\
\text { Unívoca }\end{array}$ & $\begin{array}{l}\text { Michael Arad y Peter } \\
\text { Walker (Memorial Plaza) }\end{array}$ & Nueva York - E.U.A. \\
\hline 2014 & $\begin{array}{l}\text { Memorial Nacional del } 11 \text { de } \\
\text { Septiembre - Museo Pabellón }\end{array}$ & $\begin{array}{l}\text { Espacio Museo - Narrativa } \\
\text { Plural }\end{array}$ & $\begin{array}{l}\text { Davis Brody Bond (Museo) } \\
\text { / Snohetta (Pabellón) }\end{array}$ & Nueva York - E.U.A. \\
\hline 2014 & $\begin{array}{l}\text { Lugar de la Memoria, la Tolerancia y } \\
\text { la Inclusión Social }\end{array}$ & $\begin{array}{l}\text { Espacio Museo - Narrativa } \\
\text { Plural }\end{array}$ & $\begin{array}{l}\text { Sandra Barclay \& Jean } \\
\text { Pierre Crousse }\end{array}$ & Lima - Perú \\
\hline 2012 & Casa del pueblo. El Salado & $\begin{array}{l}\text { Espacio Museo - Narrativa } \\
\text { Plural } \\
\end{array}$ & Simón Hosie & El Salado-Colombia \\
\hline 2011 & Museo Casa de la Memoria & $\begin{array}{l}\text { Espacio Museo - Narrativa } \\
\text { Plural }\end{array}$ & Juan David Botero & Medellín - Colombia \\
\hline 2011 & Museo de historia Militar de la Werh & $\begin{array}{l}\text { Espacio Museo - Narrativa } \\
\text { Plural }\end{array}$ & Daniel Libeskind & Dresde - Alemania \\
\hline 2010 & Museo de memoria y tolerancia & $\begin{array}{l}\text { Espacio Museo - Narrativa } \\
\text { Plural }\end{array}$ & Arditti + RDT & CDMX - México \\
\hline 2009 & Museo de Memoria de Andalucía & $\begin{array}{l}\text { Espacio Museo - Narrativa } \\
\text { Plural }\end{array}$ & Alberto Campo Baeza & Granada - España \\
\hline 2009 & Museo de la Memoria y los DDHH & $\begin{array}{l}\text { Espacio Museo - Narrativa } \\
\text { Plural }\end{array}$ & $\begin{array}{l}\text { Mario Figueroa, Lucas Fehr } \\
\text { y Carlos Diaz }\end{array}$ & $\begin{array}{l}\text { Santiago de Chile - } \\
\text { Chile }\end{array}$ \\
\hline 2007 & Museo Judío de Munich & $\begin{array}{l}\text { Espacio Museo - Narrativa } \\
\text { Plural } \\
\end{array}$ & $\begin{array}{l}\text { Wandel Hoefer Lorch \& } \\
\text { Hirsh }\end{array}$ & München Alemania \\
\hline 2005 & $\begin{array}{l}\text { Monmento conmemorativo KZ } \\
\text { Hinzert }\end{array}$ & $\begin{array}{l}\text { Espacio Museo - Narrativa } \\
\text { Plural }\end{array}$ & Wandel Lorch Architects & Países Bajos \\
\hline 2005 & Monumento del Holocausto & $\begin{array}{l}\text { Espacio Público - Narrativa } \\
\text { Unívoca }\end{array}$ & Peter Eisenman & Berlín - Alemania \\
\hline 2003 & Monumento Público de Mauthausen & $\begin{array}{l}\text { Espacio Museo - Narrativa } \\
\text { Plural }\end{array}$ & Werkhof Architekten & Mauthausen - Austria \\
\hline 2003 & Museo de la Herencia Judía & $\begin{array}{l}\text { Espacio Museo - Narrativa } \\
\text { Plural }\end{array}$ & KRJDA - Arquitectos & Nueva York - E.U.A. \\
\hline 2003 & Museo Judío de Dinamarca & $\begin{array}{l}\text { Espacio Museo - Narrativa } \\
\text { Plural }\end{array}$ & Daniel Libeskind & $\begin{array}{l}\text { Copenhague - } \\
\text { Dinamarca } \\
\end{array}$ \\
\hline 2002 & Museo Imperial de Guerra del Norte & $\begin{array}{l}\text { Espacio Museo - Narrativa } \\
\text { Plural }\end{array}$ & Daniel Libeskind & Manchester - Inglaterra \\
\hline 2001 & Museo del Apartheid & $\begin{array}{l}\text { Espacio Público - Narrativa } \\
\text { Unívoca }\end{array}$ & $\begin{array}{l}\text { Mashabane Rose Asso- } \\
\text { ciates }\end{array}$ & $\begin{array}{l}\text { Johannesburgo - } \\
\text { Sudáfrica }\end{array}$ \\
\hline 1999 & Museo Judío de Berlín & $\begin{array}{l}\text { Espacio Museo - Narrativa } \\
\text { Plural }\end{array}$ & Daniel Libeskind & Berlín - Alemania \\
\hline 1998 & Parque de la Memoria & $\begin{array}{l}\text { Espacio Público - Narrativa } \\
\text { Unívoca }\end{array}$ & $\begin{array}{l}\text { Varas, Lestard, Baudizzone } \\
\text { \& Ferrari }\end{array}$ & $\begin{array}{l}\text { Buenos Aires - } \\
\text { Argentina }\end{array}$ \\
\hline 1981 & $\begin{array}{l}\text { Memorial de los Veteranos de } \\
\text { Vietnam }\end{array}$ & $\begin{array}{l}\text { Espacio Público - Narrativa } \\
\text { Unívoca }\end{array}$ & Maya Lin & Washington D.C - E.U.A \\
\hline 1960 & $\begin{array}{l}\text { Monumento a los Muertos de la II } \\
\text { Guerra Mundial }\end{array}$ & $\begin{array}{l}\text { Espacio Público - Narrativa } \\
\text { Unívoca }\end{array}$ & Marcos Konder Netto & Río de Janeiro - Brasil \\
\hline 1955 & $\begin{array}{l}\text { Parque memorial de la paz } \\
\text { de Hiroshima - Esculturas } \\
\text { conmemorativas }\end{array}$ & $\begin{array}{l}\text { Espacio Público - Narrativa } \\
\text { Unívoca }\end{array}$ & Kenzo Tange & Hiroshima - Japón \\
\hline 1955 & $\begin{array}{l}\text { Parque memorial de la paz de } \\
\text { Hiroshima - Edificio Museo }\end{array}$ & $\begin{array}{l}\text { Espacio Museo - Narrativa } \\
\text { Plural }\end{array}$ & Kenzo Tange & Hiroshima - Japón \\
\hline
\end{tabular}




\section{RESCATE DE UNA MEMORIA MEDIANTE INTERVENCIONES DE CARÁCTER URBANO}

Figura 2

A Eje Ambiental Bogotá- Colombia. Fuente: fotografia del autor. obstante, el revisionismo como rescate de una memoria va más allá de la demolición de viaductos, se trata de intervenciones urbano arquitectónicas con las que se recuperan principios básicos en los que se sustentan las memorias y orígenes de la ciudad, en sintonía con valores contemporáneos como la sostenibilidad ambiental y el respeto por la historia. Desde esta óptica, acciones como rescatar la memoria del agua, borrar fronteras urbanas y/o valorar al peatón por encima del automóvil, caracterizan el sentido que moviliza este tipo revisionismo histórico en el intersticio de los siglos $X X$ y $X X \mid$, y constituyen una forma de entender la ciudad contemporánea a partir del poder transformador que detona la memoria.

Durante la década de 1940, la ciudad de Bogotá, siguiendo pautas de orden higienista y con el deseo de hacer una ciudad moderna, borró de tajo uno de los rasgos más característicos del paisaje del centro histórico de Bogotá: el río San Francisco. Esto llevó a la canalización y pavimentación de su superficie. Durante casi medio siglo el río corrió silencioso bajo el pavimento de la calle, hasta que, en 1990 los arquitectos Salmona y Kopec proyectaron un paseo peatonal con el que recobraron la presencia del río por medio de sucesivos canales, por donde anteriormente existía el cauce del antiguo río [Figura 2]. En palabras de Salmona: "las curvas asfaltadas de la Avenida Jiménez de Quesada invocan

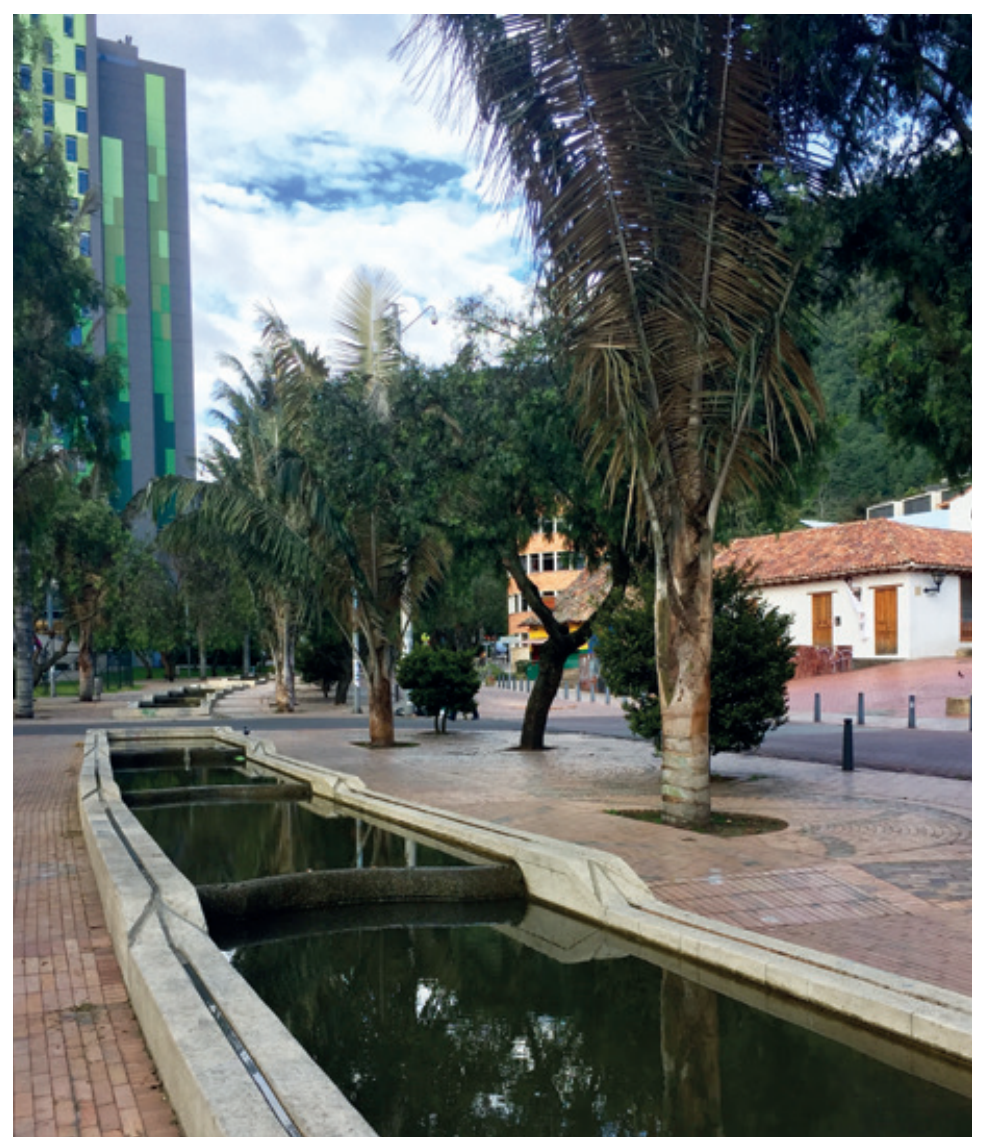




\section{RESCATAR UNA MEMORIA. INTERVENCIONES DE CARÁCTER ARQUITECTÓNICO}

3 Traducción del autor en silencio el sepultado río San Francisco o, como lo llamaron los primeros habitantes de Bogotá (los Muiscas), Viracachá, que quiere decir el resplandor del agua en la oscuridad" (Fundación Rogelio Salmona, 2020).

En estos términos, el proyecto construido recupera la memoria silenciada e invisibilizada del río, por causa de su canalización. Desde esta perspectiva, "mirar hacia atrás" se constituye en una oportunidad de redención para ciudades que han borrado apartes de su historia. Este es el caso de vastos proyectos realizados en ciudades del mundo como Boston (BIG DIG), Madrid (Madrid Río), Sao Paulo (Parque Anhangabau).

En Alemania, el palacio Real de Berlín, Palacio Schloss, fue resultado de un palimpsesto arquitectónico que entremezclaba la tipología de un castillo medieval y un palacio Renacentista, lo que motivó a Federico III (|657-17|3), rey de Prusia, a contratar al arquitecto Andreas Schluter para transformar este edificio de acuerdo con los ideales barrocos del momento. Ya en el siglo XX, durante la segunda guerra mundial, gran parte del palacio fue destruido debido a un incendio acontecido en 1945 y definitivamente demolido en 1950 por decisión de la entonces República Democrática Alemana, cuyas autoridades escépticas de querer conservar un testimonio del imperialismo Prusiano en pleno centro de la ciudad, optaron por construir en su lugar el llamado Palacio de la República. Este proyecto, del arquitecto Heinz Graffunder, fue concebido como:

un palacio para la gente, albergaba teatros, galerías de arte y cafés; y, si bien su estilo arquitectónico era un claro repudio del elitismo de su predecesor, se convirtió en el escenario de todas las grandes celebraciones y banquetes de la élite comunista. $^{3}$ (Burchard, 10 marzo 2016)

De este modo, un ícono arquitectónico de la monarquía fue borrado y reemplazado por otro ícono arquitectónico, ahora del comunismo. En un acto que, bajo el argumento de restituir el papel del pueblo -y no de la monarquía- como líder de la nación, superponía la escritura de una narrativa de la historia, sobre otra narrativa: un ejercicio de revisionismo histórico que bordea el negacionismo. Ahora bien, tras la reunificación alemana en 1989, el Palacio de la República fue cerrado al público debido a la presencia de amianto utilizado en su construcción, clausura que derivó en intensos y prolongados debates acerca del futuro del edificio, y que llevaron al parlamento alemán, en 2003, a tomar la insólita decisión de reconstruir la estereometría y las fachadas del otrora Palacio Schloss, ahora reconfigurado funcionalmente para servir como museo, a través del concurso de arquitectura convocado en 2008 y cuyo ganador fue el arquitecto Franco Stella.

A este respecto, es preciso preguntarse “¿Cómo las interpretaciones del pasado y las nuevas prácticas del recuerdo definen narrativas 


\section{DISCUSIÓN}

\section{EL NEGACIONISMO}

individuales, locales y nacionales?" (Luthar, 2013, p. 883)4. En el caso del Palacio Schloss, como en los ejemplos que se relacionan a continuación [Tabla 2], resulta evidente cómo estas "nuevas prácticas del recuerdo" han resultado predeterminantes en el rescate de una narrativa, de una memoria que se creía perdida, y en el que la arquitectura se ha constituido tanto en instrumento de "borrado", como en herramienta para la recuperación de memorias.

En el análisis de los discursos argumentativos de estos proyectos, [Tabla 2] se evidencia que la intención en común no es conmemorar un hecho, sino rememorar un espacio. En este sentido, la memoria que se rescata no es producto de un conflicto, una guerra o una violencia, sino producto de una autocrítica que la sociedad y sus dirigentes se hacen a sí mismos, con el fin de recuperar un espacio físico que se daba por perdido en la ciudad. Cabe anotar que, de las vertientes revisionistas estudiadas en esta investigación, ésta es la única que apela al desmantelamiento y desaparición de una obra como estrategia para construir una nueva, que evoque un espacio y una memoria invisibilizada de la ciudad.

\footnotetext{
En lo que se denomina revisionismo histórico hay yuxtapuestos dos sentidos del término "revisionismo". Uno, el que corresponde al procedimiento habitual de examinar algo con el propósito de mejorarlo o corregir sus posibles errores y, otro, el que refiere a la construcción de un relato histórico alternativo a otro que se impugna. (Chiaramonte, 20।3, p. 26)
}

Esta tercera acepción de "revisionismo", aquí revisada, también se ha podido confirmar en el campo de la arquitectura: una alternativa en el uso de la memoria, que no la reivindica ni la rescata, sino que, de manera deliberada, pretende negar la memoria de un pasado que se considera particularmente nocivo y/o vergonzoso para las sociedades. El negacionismo plantea entonces el desafío de borrar, ocultar, eliminar, suprimir hechos o personajes a través de un proyecto urbano arquitectónico.

Este es el caso de la vivienda donde nació Adolfo Hitler, en Austria. Una vivienda del siglo XIX que, en pleno siglo $X X \mid$, se ha convertido en símbolo de una ideología y de un victimario, cuya memoria se trata de desaparecer, en virtud de las atrocidades que representó. Al respecto, el gobierno austriaco inicialmente determinó, a través del ministro, Wolfgang Sobotka, que: "la casa de Hitler será demolida. El sótano puede quedar, pero encima se construirá un edificio nuevo" (BBC, 17 octubre 2016).

Sin embargo, posteriormente se reconsideró esta decisión: "Tras un debate profundo, hemos decidido no derribarla" para que no haya riesgo de acusaciones de querer "hacer desaparecer un capítulo de una incómoda historia", afirmó el gobernador Josef Purhinger. En cualquier caso, el edificio ya "no [podrá] ser identificado en su forma exterior" y se destinará a albergar una administración o una institución de carácter social" (Infobae, 15 diciembre 2016). A pesar de estas 
Tabla 2

Revisionismo histórico como rescate de una Memoria en arquitectura.

Fuente: Elaboración del autor.

\section{REVISIONISMO HISTÓRICO COMO RESCATE DE UNA MEMORIA A TRAVÉS DE LA ARQUITECTURA}

\begin{tabular}{|c|c|c|c|c|c|}
\hline Año & Proyecto & $\begin{array}{c}\text { Carácter de la } \\
\text { memoria recuperada }\end{array}$ & Arquitecto & Ciudad - país & Síntesis del caso \\
\hline 2020 & $\begin{array}{l}\text { Palacio Real de } \\
\text { Berlín }\end{array}$ & $\begin{array}{l}\text { Memoria } \\
\text { arquitectónica }\end{array}$ & Franco Stella & $\begin{array}{l}\text { Berlín - } \\
\text { Alemania }\end{array}$ & $\begin{array}{l}\text { El proyecto busca corregir la decisión } \\
\text { tomada por la República Democrática } \\
\text { Alemana de haber demolido el antiguo } \\
\text { palacio Real de Berlín y remplazado por } \\
\text { otro nuevo. Se reconstruye la memoria del } \\
\text { palacio original. }\end{array}$ \\
\hline 2019 & Parques del Río & $\begin{array}{l}\text { Memoria Urbano } \\
\text { ambiental }\end{array}$ & $\begin{array}{l}\text { Latitud Taller de } \\
\text { Arquitectura }\end{array}$ & $\begin{array}{l}\text { Medellín - } \\
\text { Colombia }\end{array}$ & $\begin{array}{l}\text { Este proyecto busca recuperar la memoria } \\
\text { y presencia del río Medellín, la cual se vio } \\
\text { aislada por la construcción de la Avenida } \\
\text { Regional de manera paralela al río. Ya una } \\
\text { significativa parte de esta autopista ha sido } \\
\text { soterrada, lo que ha permitido recuperar la } \\
\text { relación del río con la ciudad. }\end{array}$ \\
\hline 2014 & $\begin{array}{l}\text { Puerto Maravilla } \\
\text { - Plaza Mauá- } \\
\text { Museo del } \\
\text { Mañana }\end{array}$ & $\begin{array}{l}\text { Memoria Urbano } \\
\text { paisajística }\end{array}$ & $\begin{array}{l}\text { Ignasi Riera - } \\
\text { ABRaa - Proyec- } \\
\text { to Urbano- San- } \\
\text { tiago Caltrava } \\
\text { - Museo del } \\
\text { Mañana }\end{array}$ & $\begin{array}{l}\text { Río de Janeiro } \\
\text { - Brasil }\end{array}$ & $\begin{array}{l}\text { Recuperación de la memoria del antiguo } \\
\text { Puerto Gamboa, mediante la demolición de } \\
\text { las vías y áreas que separan la ciudad, del } \\
\text { puerto y del mar, la construcción de un túnel } \\
\text { capaz de suplir la circulación vehicular y, } \\
\text { finalmente, la construcción de plazas y áreas } \\
\text { de circulación peatonal. }\end{array}$ \\
\hline 2013 & $\begin{array}{l}\text { Bulevar del río } \\
\text { Cali }\end{array}$ & $\begin{array}{l}\text { Memoria Urbano } \\
\text { paisajística }\end{array}$ & $\begin{array}{l}\text { Elly Burckhardt } \\
\text { y Juan Manuel } \\
\text { Echeverri }\end{array}$ & $\begin{array}{l}\text { Cali - } \\
\text { Colombia }\end{array}$ & $\begin{array}{l}\text { Se corrige el aislamiento del rio Cali } \\
\text { respecto al centro histórico de la ciudad, } \\
\text { producido por la construcción de la Avenida } \\
\text { Colombia hacia 1940, recuperando así, } \\
\text { parte del sendero peatonal existente desde } \\
\text { épocas precolombinas que bordeando el } \\
\text { rio, conducía hacia el mar }\end{array}$ \\
\hline 2006 & Big Dig & $\begin{array}{l}\text { Memoria Urbano } \\
\text { paisajística }\end{array}$ & CA-T & $\begin{array}{l}\text { Boston - } \\
\text { E.U.A. }\end{array}$ & $\begin{array}{l}\text { Se revierte la decisión de haber dado pri- } \\
\text { macía al tráfico vehicular sobre el peatonal } \\
\text { a través de la realización de la I-93 como } \\
\text { viaducto, de gran impacto en el centro his- } \\
\text { tórico de la ciudad. Se demuele y se soterra } \\
\text { esta vía, recuperando la memoria del espacio } \\
\text { público existente, previa a la construcción del } \\
\text { viaducto. }\end{array}$ \\
\hline 2005 & Madrid Río & $\begin{array}{l}\text { Memoria Urbano } \\
\text { ambiental }\end{array}$ & $\begin{array}{l}\text { West 8, Burgos } \\
\text { \& Garrido, } \\
\text { Porras la Casta, } \\
\text { Rubio A. Sala }\end{array}$ & $\begin{array}{l}\text { Madrid - } \\
\text { España }\end{array}$ & $\begin{array}{l}\text { Se ajusta el aislamiento del río Mazanares } \\
\text { del entorno de la ciudad, producido por la } \\
\text { construcción de la Autopista M30 hacia 1960, } \\
\text { recuperando, así, la memoria del río como } \\
\text { parte integral de la ciudad de Madrid. }\end{array}$ \\
\hline 2005 & $\begin{array}{l}\text { Parque } \\
\text { Cheonggyecheon }\end{array}$ & $\begin{array}{l}\text { Memoria Urbano } \\
\text { paisajística }\end{array}$ & $\begin{array}{l}\text { Gobierno de } \\
\text { Seúl }\end{array}$ & Seúl-Corea & $\begin{array}{l}\text { Se trata de la regeneración del paisaje y de la } \\
\text { restitución de la memoria del río Cheonggye, } \\
\text { mediante la reestructuración de las conexiones } \\
\text { urbanas, que implicó la demolición de grandes } \\
\text { autopistas construidas en la década de } 1960 \text {. }\end{array}$ \\
\hline 2000 & Eje ambiental & $\begin{array}{l}\text { Memoria Urbano } \\
\text { ambiental }\end{array}$ & $\begin{array}{l}\text { Rogelio } \\
\text { Salmona y Louis } \\
\text { Kopec }\end{array}$ & $\begin{array}{l}\text { Bogotá - } \\
\text { Colombia }\end{array}$ & $\begin{array}{l}\text { Se revierte la decisión de haber soterrado } \\
\text { el río San Francisco; se devuelve la memoria } \\
\text { del río a la superficie como elemento primo- } \\
\text { ridal en la vivencia del eje urbano. }\end{array}$ \\
\hline 1991 & $\begin{array}{l}\text { Parque } \\
\text { Anhangabau }\end{array}$ & $\begin{array}{l}\text { Memoria Urbano } \\
\text { paisajística }\end{array}$ & Jorge Wilhem & $\begin{array}{l}\text { Sao Paulo - } \\
\text { Brasil }\end{array}$ & $\begin{array}{l}\text { Se revierte la decisión de haber dado prela- } \\
\text { ción al automovil mediante la construcción } \\
\text { de una avenida, en la década de 1990. Se } \\
\text { decide ahora soterrar la avenida y retomar } \\
\text { la memoria del espacio público. }\end{array}$ \\
\hline 1989 & $\begin{array}{l}\text { Restauración } \\
\text { Campanario } \\
\text { Catedral de } \\
\text { Pamplona }\end{array}$ & $\begin{array}{l}\text { Memoria } \\
\text { arquitectónica }\end{array}$ & Jaime Salcedo & $\begin{array}{l}\text { Pamplona - } \\
\text { Colombia }\end{array}$ & $\begin{array}{l}\text { El edificio original de la catedral data de 1797, } \\
\text { edificio que fue intervenido en } 1913 \text { y } 1926 \\
\text { para atender a las expectativas estilisticas } \\
\text { decimonónicas propias de la época. Un estu- } \\
\text { dio histórico posterior reveló la importancia } \\
\text { tipológica del edificio primitivo, por lo que el } \\
\text { nuevo proyecto de } 1988 \text { se orientó a corregir } \\
\text { la intervención de } 1926 \text {, con el fin de recuperar } \\
\text { la memoria tipológica del edificio original, re-- } \\
\text { presentada en gran parte, por su campanario. }\end{array}$ \\
\hline
\end{tabular}



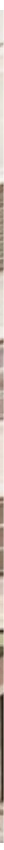

Figuras 3 y 4

Casa natalicia

de Adolfo Hitle

Inn (Austria) y

Proyecto Comisaría

Policial.

Fuente: BBC

$(17$ octubre
$2016) \cdot y$ https: / /

2016) - y https://

org/article-links/

efeeh/marte-

marte-architekten-

selected-to-

convert-hitler-s-

birthplace-into-a-

police-station-in-

austria.html intenciones, el "nuevo" edificio proyectado, será en sus dos primeros niveles igual al original. Esto, pese a que, las bases del concurso convocado para este fin, especificaran que la remodelación exterior del edificio existente tenía "que eliminar el recuerdo de la época del nacionalsocialismo" (Landsberg, 2 julio 2020).

En este proyecto arquitectónico [Figuras 3 y 4] se incurre en una doble negación: por una parte, se trata de ocultar la memoria del victimario, luego, la discusión gira exclusivamente en torno a esta memoria, sin considerar que no hay victimario sin víctimas, que la memoria que se debate aquí, no es solo la del dictador, sino la de todo un conflicto, pues esta arquitectura no representa el lugar donde nació una persona, sino el lugar donde nació una lucha.

Algo semejante ha acontecido en Medellín (Colombia), con el Concurso para el diseño de un espacio de memoria y reflexión a construirse en el lugar que ocupaba la vivienda de uno de los principales narcotraficantes del mundo moderno: Pablo Escobar. El objetivo del concurso fue: "....seleccionar la propuesta de generación de espacio público que presente la mejor materialización de un lugar para la memoria, que se preste para reflexionar sobre el pasado y para rendir homenaje de manera solemne a los valientes ..." (Sociedad Colombiana de Arquitectos, 2018, p. 10).

Aunque se menciona que debe tratarse de un lugar "para reflexionar sobre el pasado", las determinantes para el desarrollo de las propuestas del concurso, evitan a toda costa hacer alusión a dicho pasado. 


\section{DETERMINANTES PARA EL DESARROLLO DE LAS PROPUESTAS}

Ahora bien, este pasado oscuro que hace parte de la historia de Medellín quiere ser transformado por la población local y los responsables políticos, construyendo así una narrativa integral que reconoce y valora la memoria de las víctimas para la reparación simbólica y la reconciliación.

Esta decisión de reescribir la historia y confrontar los paradigmas de la llamada "narco cultura", con su narrativa de ficción y falsos héroes (películas, series, novelas), pretende construir un relato colectivo de lo que aconteció realmente, exaltando otros referentes que le pongan fin a la apología del delito y las violencias, para generar una cultura con valores que promuevan la solidaridad, la transparencia y la confianza en el otro. (Sociedad Colombiana de Arquitectos, 2018, p. 50).

Es decir, lo importante en este concurso no fue construir un lugar de memoria, sino un lugar donde materializar una tergiversación de la historia a la luz de una serie de valores, para poner "fin a la apología del delito y las violencias", ignorando que todo hecho histórico tiene causas y consecuencias, que centrar el relato solo en uno de ellos promueve automáticamente la negación del otro.

El principio básico que sustenta a los espacios de memoria es contrarrestar el olvido, al tiempo que se complejizan los relatos y se reconoce a las víctimas y a sus familias. En este concurso, por el contrario, se promueve el olvido, amputando partes de la narrativa, prohibiéndola, olvidando que no hay víctimas sin victimario, que en toda historia las consecuencias de los hechos se corresponden con una causa, que omitir estas causas, crea un vacío en el proceso que da sentido al relato, pues, ante todo, la memoria es un proceso, no un hecho. En palabras de Maurice Halbwachs: "... la clave de la ciudad no radica en la memoria como permanencia, sino en la historia como devenir" (Gorelik, 3 I agosto 2009, p.17).

Por otra parte, es importante señalar que dentro del concurso se abrió un proceso de participación ciudadana, la cual votó frente a 25 alternativas. De estas 25 ideas, solo una propuesta involucraba la conservación de la estructura del edificio (propuesta 12, que recibió el 3\% de los votos). Se escogió, en sana lógica, la propuesta de mayor votación (Propuesta 6 - Espacio público: Parque, 16\% de los votos). Este mecanismo de consulta, en principio, justifica la apuesta de intervención en el lugar, sin embargo, la cuestión que se plantea aquí, es acerca de la pertinencia de las consultas tipo referendo en temas que involucran variables tan complejas como las narrativas que implican nociones identitarias de las ciudades. El plebiscito realizado sobre los acuerdos de paz en Colombia (2016) o el referendo realizado sobre el Brexit (2015) acaso sean algunos de los principales ejemplos que cuestionan la conveniencia 
Figura 5

Propuesta concurso.

Fuente: Taller

Síntesis (2018). del uso indiscriminado de este tipo de consultas, el cual predeterminó, en el caso del concurso de Medellín, que el resultado no fuese el de un espacio de memoria, como inicialmente se había previsto, sino el de un espacio de conmemoración, es decir, del recuerdo de un hecho mediante una narrativa unívoca y parcial suministrada por el Estado.

Desde este enfoque, es de destacar el proyecto concursante elaborado por Taller Síntesis arquitectos [Figura 5] que, reconociendo el sesgo negacionista que entraña narrar una historia a medias, propuso mantener el esqueleto estructural del edificio como presencia fantasma en el nuevo proyecto. Al respecto, Taller Síntesis argumentó:

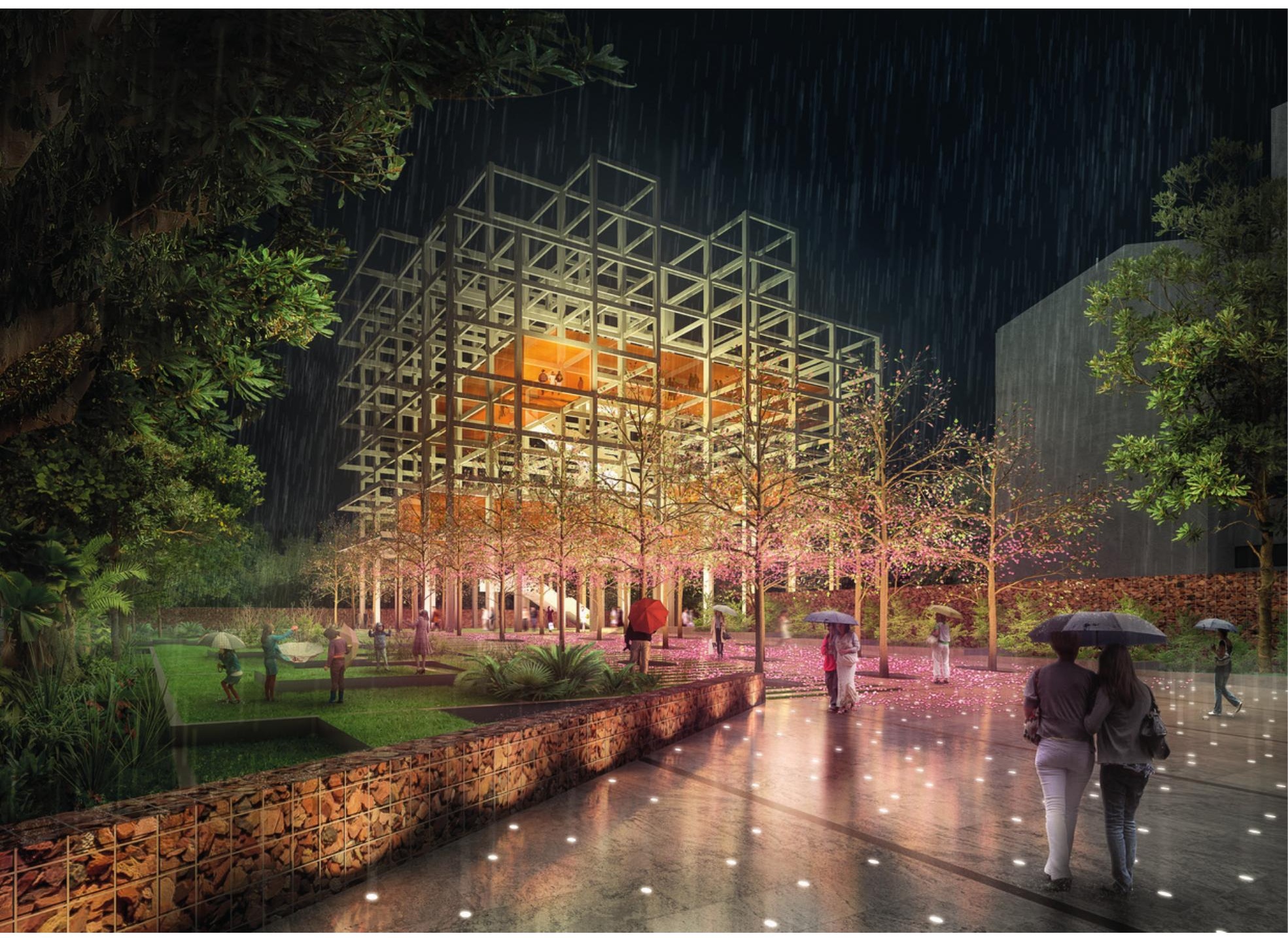


Son notorios los esfuerzos de la urbe para construir una nueva narrativa que la aleje de la etiqueta de "la ciudad más violenta del mundo" que en algún momento ostentó, sin embargo, esto también ha implicado convertir prácticamente en tabú las historias del pasado reciente...

Ocultar esta historia significa ignorar la suerte de más de ciento treinta mil personas afectadas, que entre 1980 y 2014 fueron víctimas directas del conflicto en la ciudad..., esconder los motivos que llevaron a que la ciudad viviera sus horas más oscuras y las razones por las cuales aún hoy las actividades relacionadas con el narcotráfico perviven en la ciudad. Ocultar esta historia significa eliminar el contenido de los lugares donde se dieron los hechos, borrar las voces de las víctimas, su resistencia y capacidad, no sólo de sobrevivir, sino de transformar su realidad. (Taller Síntesis 2018)

Esta propuesta no ganadora del concurso ilustra -en abierta contradicción a las bases establecidas por el gobierno- la necesidad de reconocer a todos los protagonistas del conflicto, evitando centrar la mirada en una sola parte de la historia del narcotráfico, la de las víctimas, mediante un proyecto arquitectónico que evidencia las tensiones que caracterizaron este drama en Colombia, representadas en el parque, el lugar de memoria, y la ruina del edificio Mónaco, elocuente huella de lo que no podrá volver a ser jamás.

Por último, se presenta una relación de proyectos, donde el negacionismo caracteriza el sentido de estas obras, en tanto línea de acción del revisionismo histórico tendiente a negar, a través de la arquitectura, una memoria en particular [Tabla 3]. La lectura cruzada entre los proyectos y sus discursos justificatorios permitió detectar un factor en común en estos proyectos negacionistas: se trata de intervenciones ordenadas desde un poder hegemónico (un gobierno, la iglesia, una alcaldía) que se sobrepone a la decisión de otro poder igualmente hegemónico, con el objetivo de imponer una visión de la historia en la ciudad y, por ende, en la ciudadanía. 
Tabla 3

Revisionismo histórico como negación de una memoria a través de la arquitectura.

Fuente: Elaboración del autor

\section{REVISIONISMO HISTÓRICO COMO NEGACIÓN DE UNA MEMORIA A TRAVÉS DE LA AROUITECTURA}

\begin{tabular}{|c|c|c|c|c|c|}
\hline Año & Proyecto & $\begin{array}{c}\text { Carácter de la } \\
\text { memoria negada }\end{array}$ & Arquitecto & $\begin{array}{l}\text { Ciudad - } \\
\text { país }\end{array}$ & Síntesis del caso \\
\hline 2019 & $\begin{array}{l}\text { Parque Inflexión - } \\
\text { Concurso Espacio } \\
\text { Memoria 1983-1994 } \\
\text { - Edificio Mónaco }\end{array}$ & Memoria Social & $\begin{array}{l}\text { Taller Alterno, } \\
\text { Pequeña Escala } \\
\text { Arquitectura y } \\
\text { Luis Felipe Zapata } \\
\text { Flórez. }\end{array}$ & $\begin{array}{l}\text { Medellin - } \\
\text { Colombia }\end{array}$ & $\begin{array}{l}\text { Al otorgar el premio del concurso a una } \\
\text { propuesta que borra el recuerdo del vic- } \\
\text { timario, siguiendo las pautas previstas en } \\
\text { las bases del concurso, se está negando } \\
\text { su memoria, haciendo de este proyecto } \\
\text { no un lugar de memoria, sino un lugar de } \\
\text { conmemoración. }\end{array}$ \\
\hline 2019 & $\begin{array}{l}\text { Concurso para la } \\
\text { Casa de Hitler }\end{array}$ & Memoria Política & $\begin{array}{l}\text { Marte. Marte } \\
\text { Arquitectos } \\
\text { (modificación) }\end{array}$ & $\begin{array}{l}\text { Salzburgo - } \\
\text { Austria }\end{array}$ & $\begin{array}{l}\text { Se busca ocultar la memoria de la casa } \\
\text { como lugar de nacimiento de Adolfo } \\
\text { Hitler, se considera solamente la memoria } \\
\text { del víctimario, evitando hacer mención a } \\
\text { la memoria de las víctimas. }\end{array}$ \\
\hline 2008 & $\begin{array}{l}\text { Penitenciaría de } \\
\text { San Luis Potosí / } \\
\text { Centro de las Artes }\end{array}$ & $\begin{array}{l}\text { Memoria } \\
\text { Patrimonial }\end{array}$ & $\begin{array}{l}\text { Arq. Carlos } \\
\text { Suárez (proyecto } \\
\text { original) Arq. } \\
\text { Alejandro Sánchez } \\
\text { (modificación) }\end{array}$ & $\begin{array}{l}\text { San Luis } \\
\text { Potosi - } \\
\text { Mexico }\end{array}$ & $\begin{array}{l}\text { Se borra la memoria del edificio histórico } \\
\text { en tanto se "limpia" de toda referencia al } \\
\text { uso original como penitienciaría, con el fin } \\
\text { de conservar solamente aquellos aspectos } \\
\text { históricos del edificio, que aludan a una } \\
\text { condición cultural en su, ahora nueva fun- } \\
\text { cionalidad, como Centro de las Artes. }\end{array}$ \\
\hline 1998 & $\begin{array}{l}\text { Palacio de Justicia } \\
\text { Alfonso Reyes } \\
\text { Echandía }\end{array}$ & Memoria Política & $\begin{array}{l}\text { Arq. Roberto } \\
\text { Londoño }\end{array}$ & $\begin{array}{l}\text { Bogotá - } \\
\text { Colombia }\end{array}$ & $\begin{array}{l}\text { Se borra la memoria del holocausto acon- } \\
\text { tecido en 1985, al evitar cualquier semejan- } \\
\text { za y alusión a la primera versión del Palacio, } \\
\text { y al hecho histórico que allí ocurrió. }\end{array}$ \\
\hline 1976 & $\begin{array}{l}\text { Palacio de la } \\
\text { República (RDA) }\end{array}$ & Memoria Política & $\begin{array}{l}\text { Arq. Heinz } \\
\text { Graffunder }\end{array}$ & $\begin{array}{l}\text { Berlín - } \\
\text { Alemania }\end{array}$ & $\begin{array}{l}\text { Se borra la memoria del Imperio Prusia- } \\
\text { no, contrario a los principios comunistas } \\
\text { de la República Democràtica Alemana, } \\
\text { al demoler el palacio Real Barroco y } \\
\text { proyectar en el mismo lugar el Palacio de } \\
\text { la República. }\end{array}$ \\
\hline 1948 & $\begin{array}{l}\text { Proyecto Centro } \\
\text { Cívico de Bogotá }\end{array}$ & $\begin{array}{l}\text { Memoria } \\
\text { Patrimonial }\end{array}$ & Le Corbusier & $\begin{array}{l}\text { Bogotá - } \\
\text { Colombia }\end{array}$ & $\begin{array}{l}\text { Se pretende borrar la memoria urbana de } \\
\text { la ciudad, superponiendo una morfología } \\
\text { "moderna" a la morfología de damero } \\
\text { propia del trazado fundacional de la ciu- } \\
\text { dad, de la cual se mantendrían únicamen- } \\
\text { te } 9 \text { manzanas históricas fundacionales. }\end{array}$ \\
\hline 1948 & $\begin{array}{l}\text { Panóptico de } \\
\text { Bogotá /Museo } \\
\text { Nacional de } \\
\text { Colombia }\end{array}$ & $\begin{array}{l}\text { Memoria } \\
\text { Patrimonial }\end{array}$ & $\begin{array}{l}\text { Arq. Thomas } \\
\text { Reed (proyecto } \\
\text { original) Ing. } \\
\text { Jorge Camacho } \\
\text { (modificación) } \\
\end{array}$ & $\begin{array}{l}\text { Bogotá - } \\
\text { Colombia }\end{array}$ & $\begin{array}{l}\text { Se elimina la memoria del lugar de prisión, } \\
\text { suprimiendo todo rasgo arquitectónico } \\
\text { alusivo a la función de penitenciaría y } \\
\text { abriendo los espacios para albergar la co- } \\
\text { lección del Museo Nacional de Colombia. }\end{array}$ \\
\hline $\begin{array}{l}1438 \\
\text { Templo } \\
-1538 \\
\text { Iglesia }\end{array}$ & $\begin{array}{l}\text { Templo Qui Kancha } \\
\text { / Iglesia Santo } \\
\text { Domingo }\end{array}$ & $\begin{array}{l}\text { Memoria } \\
\text { Patrimonial }\end{array}$ & N.D. & Lima - Perú & $\begin{array}{l}\text { Templo Incaico dedicado a la adoración } \\
\text { del Sol, saqueado en } 1534 \text { durante el } \\
\text { proceso de colonización, lo que derivó } \\
\text { en la construcción de la lglesia de Santo } \\
\text { Domigo, por parte de la Comiunidad de } \\
\text { los Dominicos, encima de las cimientes } \\
\text { del otrora Templo Incaico. }\end{array}$ \\
\hline c.a. 1524 & $\begin{array}{l}\text { Centro ceremonial } \\
\text { Azteca / Centro } \\
\text { histórico de Ciudad } \\
\text { de México }\end{array}$ & $\begin{array}{l}\text { Memoria } \\
\text { Patrimonial }\end{array}$ & $\begin{array}{l}\text { (Alarife) } \\
\text { Alonso García } \\
\text { (modifcación) }\end{array}$ & $\begin{array}{l}\text { CDMX - } \\
\text { México }\end{array}$ & $\begin{array}{l}\text { Se intenta borrar la memoria del Imperio } \\
\text { Azteca cuando los españoles deciden des- } \\
\text { truir el centro ceremonial y sobre él fundar } \\
\text { parte del nuevo centro de la ciudad. }\end{array}$ \\
\hline $\begin{array}{l}785 \\
\text { Mezquita } \\
-1.236 \\
\text { Catedral }\end{array}$ & $\begin{array}{l}\text { Iglesia / Mezquita } \\
\text { /Catedral de } \\
\text { Córdoba }\end{array}$ & $\begin{array}{l}\text { Memoria } \\
\text { Patrimonial }\end{array}$ & $\begin{array}{l}\text { Hernan Ruiz et al. } \\
\text { (Catedral) }\end{array}$ & $\begin{array}{l}\text { Córdoba - } \\
\text { España }\end{array}$ & $\begin{array}{l}\text { Iglesia cristiana dedicada a San Vicente } \\
\text { Mártir, demolida por Abderramán I para } \\
\text { la construcción de la nueva Mezquita } \\
\text { de Córdoba tras la conquista islámica } \\
\text { de la península ibérica (711 - } 726 \text { d.c.) y } \\
\text { reconvertida, más de } 5 \text { siglos después a } \\
\text { Catedral consagrada a la virgen María; } \\
\text { la Mezquita - Catedral de Córdoba es un } \\
\text { estudio de caso que no solo comporta } \\
\text { una sucesiva transformación espacial, } \\
\text { sino un infructuoso intento por negar una } \\
\text { memoria que por siglos caracterizó a los } \\
\text { ciudadanos de la región de Andalucía. }\end{array}$ \\
\hline
\end{tabular}




\section{CONCLUSIONES}

Como punta de iceberg que advierte un fenómeno mucho más grande del que aparentemente se aprecia, la arquitectura se revela en las ciudades, en tanto manifestación visible, de una suma de procesos, no visibles a simple vista. Así, el revisionismo histórico en arquitectura se plantea entonces, como la revisión de ese "iceberg sumergido", de esa ciudad conformada no solo de arquitectura sino de hechos, decisiones, acuerdos y conflictos que, en suma, conforman la memoria de una ciudad. Por lo tanto, estamos ante la aparición no de un nuevo fenómeno, sino de un inusitado proceso de concientización y sensibilización de los distintos fenómenos que hemos acumulado a lo largo del tiempo. Un revisionismo cuya particularidad radica en que no surge de los historiadores, de la academia, ni de ningún poder hegemónico, sino de sectores de la sociedad cuyas acciones revisionistas en la ciudad, revelan un modo de ver el pasado de la ciudad y un modo de pensar, a la vez, el pasado y el futuro de la sociedad.

La búsqueda y activación de memorias silenciadas es un signo de los últimos tiempos, que motivó la pregunta de la investigación que aquí se ha expuesto: ¿cómo hacerlo?, ¿cómo unas memorias se imponen a otras en arquitectura? Buscarlas es una tarea que, desde hace un buen tiempo, se viene realizando desde disciplinas como la historia, la sociología o la antropología. En arquitectura, el reto no es solo historiografiar críticamente estas memorias, pues aquella es una tarea que ya se ha emprendido, en parte, a través de posturas como el decolonialismo. El reto tiene que ver con los modos en que la arquitectura es utilizada para activar una memoria, una materialización que no solo dé paso al esteticismo o a la consolidación de narrativas unívocas, sino que, por el contrario, dé lugar a la generación de memorias plurales y en permanente construcción, que contribuyan, en parte, a romper un mundo tan polarizado como el que vivimos hoy. Las arquitecturas para la reivindicación y el rescate de una memoria, dan cuenta de dos de estos modos de activar memorias silenciadas; una tercera vía, el negacionismo, muestra el más radical camino para la imposición de una memoria sobre otras.

La paradoja es que, entre más arquitectura se produce para reivindicar o rescatar una memoria, más datos e información se seguirá descubriendo y recordando, lo cual genera en estas arquitecturas un permanente esfuerzo por crear mecanismos y espacios para recordar y no olvidar nada, como un Funes el memorioso, cuyo permanente esfuerzo por recordarlo todo, le mantenía siempre anclado en un pasado que le impedía pensar en un futuro.

Ante el peso de una historia acumulada a lo largo de siglos de existencia, las ciudades y las sociedades actuales ya no se proyectan solamente a partir de una visión positivista de progreso, sino de una visión retrospectiva que les permite sobrellevar y enfrentar el peso de su pasado. Esta visión de un "futuro retrospectivo" ha 
derivado en un modo alternativo de desarrollo de las ciudades, a partir de una revisión crítica de su historia, en el que los arquitectos pueden, con sus intervenciones, hacer de la arquitectura un instrumento para la reivindicación y/o el rescate de una memoria. Así, se confirma cómo el revisionismo histórico, en tanto postura característica del mundo contemporáneo, ha trascendido de las ciencias sociales y se ha extendido a la arquitectura, como materialización física de una reflexión crítica de la sociedad sobre su propio pasado, un revisionismo que reitera a la arquitectura como herramienta de escritura de las ciudades, pero también como instrumento supresor de su historia. 


\section{REFERENCIAS BIBLIOGRÁFICAS}

AGUILAR-FORERO, N. (2018). Políticas de la memoria en Colombia: iniciativas, tensiones y experiencias (2005-2016). Historia Crítica, (68), 111-130.

BBC Mundo (17 octubre 2016). Austria anuncia que la casa de Hitler será demolida. Recuperado de: https://www.bbc.com/mundo/noticias-internacional-37683525

BURCHARD, W. (2016). What's the point of rebuilding Germany's palaces? Apollo Art Magazine. Recuperado de https://www.apollo-magazine.com/ whats-the-point-of-rebuilding-germanys-palaces/

CAPITEL, A. (1997). Arquitectura europea y americana después de las vanguardias. La arquitectura revisionista y orgánica en Estados Unidos. Madrid: Espasa Calpe.

CHIARAMONTE, J. (2013). Usos políticos de la historia. Lenguaje de clases y revisionismo histórico. Buenos Aires: Sudamericana.

ERLL, A. (2012). Memoria colectiva y culturas del recuerdo estudio introductorio. Bogotá: Uniandes.

FERNÁNDEZ GALIANO, L. (2009). La diferencia indiferente. AV: Monografías, (139), 3-5.

Fundación Rogelio Salmona (2001). Recuperación del eje ambiental avenida Jiménez de Quesada. Recuperado de http://obra.fundacionrogeliosalmona.org/ obra/proyecto/recuperacion-del-eje-ambiental-avenida-jimenez-de-quesada/

GORELIK, A. (31 agosto 2009). Arquitectura y Memoria. Memoria abierta. Actas Jornada Arquitectura y Memoria (pp. 16-23), Buenos Aires, Argentina. Recuperado de http://memoriaabierta.org.ar/wp/wp-content/uploads/2018/07/Arquitectura-y-Memoria-Memoria-Abierta.pdf

Gobierno de España (2007). Ley de la memoria histórica. Ley 52/2007 por la que se reconocen y amplían derechos y se establecen medidas en favor de quienes padecieron persecución o violencia durante la guerra civil y la dictadura. Madrid. Infobae (15 diciembre 2016). Finalmente, Austria expropiará la casa natal de Adolf Hitler, pero no la demolerá. Recuperado de https://www.infobae. com/america/mundo/2016/12/15/finalmente-austria-expropiara-la-casa-natal-de-adolf-hitler-pero-no-la-demolera/ (2016)

JARAMILLO, J. Y DEL CAIRO, C. (2013). Los dilemas de la museificación. Reflexiones en torno a dos iniciativas estatales de construcción de memoria colectiva en Colombia. Memoria y Sociedad, 17(35), 76-92.

KLEIN, N. (2010). ¿Dónde queda el olvido? Una nota acerca del padre de Borges. En Plot, M. (comp.), Destino sudamericano (pp. 209 -216). Buenos Aires: Teseo.

LANDSBERG, T. (2 julio 2020). La casa natal de Hitler se convertirá en una comisaría de Policía. DW. Recuperado de https://www.dw.com/es/la-casa-natal-de-hitler-se-convertir\%C3\%A1-en-una-comisar\%C3\%ADa-de-polic\%C3\%ADa/a-54019844

LUTHAR, O. (2013). Forgetting does (not) hurt. Historical Revisionism in Post-Socialist Slovenia. Nationalities Papers, 41(6), 882-892.

MARTín BARBERO, J. (2010). Mutaciones culturales y estéticas de la política. Revista de Estudios Sociales, (35), 15-25.

MONTANER, J. Y MUXI, Z. (2011). Arquitectura y política. Ensayos para mundos alternativos. Madrid: Gustavo Gili.

MORRILL, J. (2015). Revisionism's Wounded Legacies. Huntington Library Quarterly, 78(4), 577-594. Recuperado de http://www.jstor.org/stable/10.1525/ hlq.2015.78.4.577

Museo Reina Sofía - Subtramas. Abecedario anagramático. Recuperado de http://subtramas.museoreinasofia.es/es/anagrama/agenciamiento

Sociedad Colombiana de Arquitectos (2018). Bases. Concurso público internacional anteproyecto arquitectónico para el diseño de un Espacio de memoria y reflexión, Medellín 1983 - 1994. Bogotá.

Taller Síntesis (2018). Memoria descriptiva. Concurso público internacional de anteproyecto arquitectónico para el diseño de un Espacio de memoria y reflexión, Medellín 1983 - 1994. Plancha 1 de 2. Recuperado de https://www. archdaily.co/co/908185/esta-es-la-propuesta-de-taller-sintesis-para-el-edificio-monaco-en-medellin

VON HENNEBERG, K. (2004). Monuments, Public Space, and the memory of Empire in Modern Italy. History and Memory, 16(1), 37-85. 